\title{
META ANALISIS GRATITUDE INTERVENTION PADA WELL-BEING
}

\author{
Levina Wicaksono \\ E-mail: angelinelevinaw@gmail.com \\ Universitas Surabaya, Fakultas Psikologi, Magister Psikologi Profesi
}

\begin{abstract}
Abstrak
Well-being merupakan salah satu aspek penting dalam hidup individu. Well-being yang tinggi diasosiasikan dengan umur panjang dan kurangnya risiko kematian pada individu dengan pola hidup yang sehat. Penelitian meta analisis ini dilakukan untuk mengetahui efektifitas gratitude intervention terhadap well-being. Penelitian ini menganalisa 12 literatur penelitian untuk menguji efektifitas gratitude intervention pada wellbeing. Hasil dari meta analisis menunjukkan effect size yang didapatkan nilai pooled d+ sebesar 0.238184 (d $>0.2$ ) dengan tingkat kepercayaan sebesar $95 \%$. Hal ini dapat diartikan gratitude intervention cukup efektif dalam mempengaruhi well-being individu
\end{abstract}

Kata kunci: Gratitude Intervention, Well-Being, Gratitude

\section{Abstract}

Well-being is an important aspect of an individual's life. High well-being is associated with long life and lower death risk on healthy individual. The purpose of this meta analysis study is to know the effectiveness of gratitude intervention on well-being. This study analyzes 12 literatures to test the effectiveness of gratitude intervention on well-being. The results of meta analysis shown pooled $d+$ score of $0.238184(d>0.2)$ with 95\% CI. It means gratitude intervention is moderately effective on individual's well being.

Keywords: Gratitude Intervention, Well-Being, Gratitude

\section{PENDAHULUAN}

Well-being merupakan sebuah kondisi ketika individu sejahtera baik secara fisik, mental, dan sosial (Krawczynski dan Olszewski, 2000 disitat dalam Sadeghi dan Pow, 2015). Menurut Ryff (Sadeghi dan Pow, 2015), well-being didefinisikan sebagai usaha yang dilakukan oleh individu untuk mencapai pemenuhan kemampuan potensial individu. Pada well-being terdapat dua jenis yaitu psychological well-being dan subjective well-being. Ryff, et al. (Sadeghi dan Pow, 2015) mengkategorisasikan psychological wellbeing ke dalam enam faktor yaitu, penerimaan diri, tujuan hidup, pengembangan diri, environmental mastery, relasi positif, dan autonomi. Sedangkan subjective well-being terdiri dari dua komponen yaitu, afektif dan kognitif. Komponen afektif terdiri dari afek positif dan afek negatif, sedangkan komponen kognitif cenderung mengarah kepada kepuasan hidup individu. Subjective well-being dikenal juga dengan sebutan kebahagiaan (Diener disitat dalam Sadeghi dan Pow, 2015).

Well-being dapat dikatakan sebagai salah satu aspek penting dalam hidup individu. Terdapat dampak-dampak positif saat individu dapat mencapai kesejahteraan dalam hidupnya. Penelitian yang dilakukan oleh Chida dan Steptoe (2008 disitat dalam Diener dan Chan, 2011) menyatakan orang yang memiliki 
psychological well-being positif, memiliki tingkat kematian yang lebih rendah. Emosi-emosi positif dan kepuasan hidup juga diasosiasikan dengan umur panjang, berkurangnya risiko kematian pada individu yang sehat, dan pengontrolan terhadap hal-hal negatif dalam hidup individu (Diener dan Chan, 2011).

Gratitude merupakan salah satu konstruk yang dapat memengaruhi wellbeing. Gratitude dapat memengaruhi well-being secara langsung maupun tidak langsung. Gratitude memengaruhi wellbeing secara tidak langsung dengan menjadi peredam terhadap emosi-emosi negatif (Nelson, 2009 disitat dalam Killen dan Macaskill, 2014). Gratitude, menurut Park et al. (Killen dan Macaskill, 2014), berhubungan erat dengan kepuasan hidup dan well-being. Gratitude adalah pengakuan bahwa kita telah menerima sesuatu yang berharga dari orang lain (Emmons dan Mishra disitat dalam Killen dan Macaskill, 2014). Gratitude biasanya meliputi beberapa hal yaitu, apresiasi, rasa terima kasih, dan rasa takjub (Emmons dan Shelton, 2002 disitat dalam Toepfer dan Walker, 2009). Gratitude terdiri dari dua fase, fase pertama adalah individu menyadari hal positif yang telah diterima, lalu fase kedua adalah individu menyadari bahwa orang lain memiliki peran dalam penerimaan hal positif tersebut (Weiner, 1985 disitat dalam Sadeghi dan Pow, 2015).

Terdapat banyak penelitian mengenai pemberian gratitude intervention untuk meningkatkan wellbeing. Berdasarkan penelitian-penelitian yang telah dilakukan, sebagian besar menemukan gratitude intervention mampu meningkatkan well-being subjek penelitian. Gratitude intervention dapat mencegah terjadinya konflik antar individu dan dapat meningkatkan dukungan sosial yang dimiliki oleh individu (Otsuka, Hori, dan Kawahito, 2012). Namun terdapat penelitian yang mendapatkan hasil yang berlawanan. Penelitian yang dilakukan oleh Winslow, Kaplan, Geist, Lindsey, Ahmad, dan Hargrove, 2016) menemukan gratitude intervention tidak memiliki efek yang signifikan terhadap skor well-being peserta intervensi. Melihat adanya inkonsistensi pada hasil penelitian terdahulu, peneliti merasa penting untuk meneliti lebih lanjut mengenai keefektivitasan gratitude interventions terhadap well-being.

\section{METODE PENELITIAN}

\section{Studi Literatur}

Pencarian penelitian yang dilakukan menggunakan kata kunci "gratitude intervention", "gratitude intervention on well-being", "well-being”, 
dan "gratitude therapy". Proses pencarian penelitian dilakukan melalui situs jurnal elektronik seperti Science Direct dan menggunakan media Google.

\section{Inklusi}

Kriteria yang digunakan pada penelitian ini berupa (1) diterbitkan dalam 10 tahun terakhir (2010-2021), (2) memiliki kelompok kontrol dan kelompok eksperimen, (3) menuliskan nilai mean (M) dan standar deviasi (SD) pada pretest dan posttes di kelompok eksperimen dan kelompok kontrol, (4) ditulis dalam bahasa Inggris, dan (5) menuliskan jumlah partisipan penelitian (N).

\section{Pengolahan Data}

Setelah mengumpulkan literatur yang sesuai dengan kriteria, peneliti mengumpulkan data terkait (1) nama peneliti dan tahun penelitian, (2) jumlah partisipan pada pretest dan posttest, (3) usia partisipan, (4) durasi intervensi, (5) standar deviasi dan mean kelompok eksperimen dan kelompok kontrol pada pretest dan posttest, Hasil data yang dikumpulkan dapat dilihat pada tabel 1 dan tabel 2.

Meta analisis dilakukan untuk melihat effect size gratitude intervention terhadap well-being. Selain itu, peneliti juga menguji heterogenitas data penelitian dan inconsistency penelitian. Effect size dibagi menjadi tiga kategori yaitu kecil, sedang, dan besar dengan ketentuan effect size dikatakan kecil ketika d < 0.2 , sedang ketika $\mathrm{d}<0.5$, dan tinggi ketika d $>0.8$.

\section{HASIL PENELITIAN DAN} PEMBAHASAN

\section{Included Studies}

Dari pencarian yang dilakukan, peneliti menemukan 14 penelitian yang meneliti tentang gratitude intervention pada well-being. 2 penelitian tidak digunakan dikarenakan tidak adanya SD pada tabel pretest-posttest. Daftar literatur yang digunakan dapat dilihat pada tabel 1 . Tabel 2 berisi data skor post-test dan pretest kelompok eksperimen dan kelompok kontrol studi literatur yang digunakan.

Berikut pada tabel 1 di bawah ini disajikan daftar literatur yang digunakan. 
Tabel 1 Daftar Studi Literatur yang Digunakan

\begin{tabular}{|c|c|c|c|c|c|c|}
\hline No. & Peneliti & Outcomes & $\begin{array}{c}\text { Usia } \\
\text { (atau } \\
\text { M) }\end{array}$ & $\begin{array}{c}\text { Experimental } \\
\text { Group } \\
\text { Intervention }\end{array}$ & $\begin{array}{l}\text { Control Group } \\
\text { Intervention }\end{array}$ & Durasi \\
\hline 1 & $\begin{array}{l}\text { Duthley, Nunn, dan } \\
\text { Avella (2017) }\end{array}$ & Life satisfaction & $13-15$ th & $\begin{array}{l}\text { Gratitude- } \\
\text { meditation } \\
\text { intervention }\end{array}$ & No treatment & $\begin{array}{l}15-20 \\
\text { menit, } 10 \\
\text { sesi }\end{array}$ \\
\hline 2 & $\begin{array}{l}\text { Watkins, Uhder, dan } \\
\text { Pichinevskiy (2014) }\end{array}$ & Well-being & $>18$ th & $\begin{array}{l}\text { Gratitude 3- } \\
\text { blessings }\end{array}$ & Memory placebo & 1 minggu \\
\hline 3 & $\begin{array}{l}\text { Toepfer, Cichy, dan } \\
\text { Peters (2011) }\end{array}$ & Happiness & $\begin{array}{l}18-65 \\
\text { th }\end{array}$ & Gratitude letters & No treatment & 4 minggu \\
\hline 4 & $\begin{array}{ll}\text { Rash, } & \text { Matsuba, } \\
\text { dan } & \text { Prkachin } \\
(2011) & \end{array}$ & $\begin{array}{l}\text { Satisfaction } \\
\text { with life }\end{array}$ & 22.5 th & $\begin{array}{l}\text { Gratitude } \\
\text { contemplation } \\
\text { intervention } \\
\text { program }\end{array}$ & $\begin{array}{l}\text { Memorable events } \\
\text { contemplation } \\
\text { intervention program }\end{array}$ & $\begin{array}{l}2 \text { kali } \\
\text { selama } 4 \\
\text { minggu }\end{array}$ \\
\hline 5 & $\begin{array}{l}\text { Killen dan } \\
\text { Macaskill (2014) }\end{array}$ & $\begin{array}{l}\text { Eudamonic } \\
\text { well- being }\end{array}$ & $60-91$ th & $\begin{array}{l}\text { Paper based three } \\
\text { good things in life } \\
\text { intervention }\end{array}$ & $\begin{array}{l}\text { Online based three } \\
\text { good things in life } \\
\text { intervention }\end{array}$ & 14 hari \\
\hline 6 & $\begin{array}{l}\text { Tyler, Renshaw, dan } \\
\text { Rock (2018) }\end{array}$ & $\begin{array}{l}\text { Life } \\
\text { Satisfaction }\end{array}$ & $17-31$ th & $\begin{array}{l}\text { Grateful thinking } \\
\text { only exercises }\end{array}$ & $\begin{array}{l}\text { Activity-matched } \\
\text { exercises }\end{array}$ & 2 minggu \\
\hline 7 & $\begin{array}{l}\text { Timmons dan Ekas } \\
(2018)\end{array}$ & $\begin{array}{l}\text { Life } \\
\text { Satisfaction }\end{array}$ & 39.70 th & $\begin{array}{l}\text { General gratitude } \\
\text { letter intervention }\end{array}$ & Neutral life-events let & $\begin{array}{l}1 \text { sesi per } \\
\text { minggu }\end{array}$ \\
\hline 8 & $\begin{array}{l}\text { Khanna dan Singh } \\
\text { (2016) }\end{array}$ & $\begin{array}{l}\text { Pyschological } \\
\text { well-being }\end{array}$ & $11-14$ th & $\begin{array}{l}\text { Gratitude } \\
\text { curriculum session }\end{array}$ & $\begin{array}{l}\text { Attention focused } \\
\text { training }\end{array}$ & $\begin{array}{l}\text { selama } 8 \\
30 \text { menit } \\
\text { per minggu } \\
\text { selama } 5\end{array}$ \\
\hline 9 & $\begin{array}{l}\text { Sadeghi dan Pow } \\
\text { (2015) }\end{array}$ & Happiness & $\begin{array}{l}21-46 \\
\text { th }\end{array}$ & Gratitude training & No treatment & $\begin{array}{l}90 \text { menit, } 1 \\
\text { sesi } \\
\text { perminggu }\end{array}$ \\
\hline 10 & $\begin{array}{l}\text { Otsuka, Hori, dan } \\
\text { Kawahito (2012) }\end{array}$ & $\begin{array}{l}\text { Life } \\
\text { Satisfaction }\end{array}$ & 48,5 th & Gratitude journal & Neutral work event & 4 minggu \\
\hline 11 & $\begin{array}{l}\text { Soshani dan } \\
\text { Steinmetz (2013) }\end{array}$ & $\begin{array}{l}\text { Life } \\
\text { Satisfaction }\end{array}$ & $13-75$ th & $\begin{array}{l}\text { Positive } \\
\text { psychology school }\end{array}$ & No treatment & 1 tahun \\
\hline 12 & $\begin{array}{l}\text { Wong, Owen, } \\
\text { Gabana, Brown, } \\
\text { Mcinnis, Toth, dan }\end{array}$ & $\begin{array}{l}\text { Positive } \\
\text { emotions }\end{array}$ & $>18$ th & Gratitude writing & Expressive writing & $\begin{array}{l}20 \text { menit, } 1 \\
\text { sesi } \\
\text { perminggu }\end{array}$ \\
\hline
\end{tabular}

Tabel 2 Daftar Skor Post-test dan Pre-test Literatur yang Digunakan

\begin{tabular}{|c|c|c|c|c|c|c|c|c|c|c|c|c|c|}
\hline \multirow{3}{*}{ No. } & \multirow{3}{*}{ Peneliti } & \multicolumn{6}{|c|}{ Experimental Group } & \multicolumn{6}{|c|}{ Control Group } \\
\hline & & \multicolumn{3}{|c|}{ Pre-Test } & \multicolumn{3}{|c|}{ Post-Test } & \multicolumn{3}{|c|}{ Pre-Test } & \multicolumn{3}{|c|}{ Post-Test } \\
\hline & & SD & Mean & $\mathbf{N}$ & SD & Mean & $\mathbf{N}$ & SD & Mean & $\mathbf{N}$ & SD & Mean & $\mathbf{N}$ \\
\hline 1 & $\begin{array}{l}\text { Duthley, Nunn, } \\
\text { dan Avella } \\
(2017)\end{array}$ & 5.1 & 35.3 & 30 & 5.8 & 39.7 & 30 & 6.3 & 35.5 & 25 & 7.9 & 34.2 & 25 \\
\hline 2 & $\begin{array}{l}\text { Watkins, Uhder, } \\
\text { dan Pichinevskiy } \\
(2014)\end{array}$ & 2.37 & -0.57 & 47 & 2.38 & 0.65 & 47 & 2.74 & -1.23 & 40 & 2.55 & -0.036 & 40 \\
\hline 3 & $\begin{array}{l}\text { Toepfer, Cichy, } \\
\text { dan Peters (2011) }\end{array}$ & 3.9 & 19.72 & 105 & 3.8 & 20.62 & 105 & 4.28 & 19.68 & 78 & 4.16 & 19.58 & 78 \\
\hline 4 & $\begin{array}{l}\text { Rash, Matsuba, } \\
\text { dan Prkachin } \\
\text { (2011) }\end{array}$ & 6.48 & 25.36 & 28 & 4.47 & 27.27 & 28 & 4.28 & 27.84 & 28 & 4.79 & 26.92 & 28 \\
\hline 5 & $\begin{array}{l}\text { Killen dan } \\
\text { Macaskill (2014) }\end{array}$ & 7.66 & 43.93 & 40 & 6.37 & 45.83 & 40 & 6.02 & 44.58 & 48 & 5.89 & 46.25 & 48 \\
\hline 6 & $\begin{array}{l}\text { Tyler, Renshaw, } \\
\text { dan Rock (2018) }\end{array}$ & 6.99 & 23.89 & 54 & 5.69 & 25.74 & 54 & 6.25 & 24.47 & 43 & 5.44 & 24.79 & 43 \\
\hline 7 & $\begin{array}{l}\text { Timmons dan } \\
\text { Ekas (2018) }\end{array}$ & 4.31 & 14.88 & 26 & 5.22 & 15.83 & 24 & 4.59 & 14.90 & 29 & 4.44 & 16.76 & 21 \\
\hline 8 & $\begin{array}{l}\text { Khanna dan } \\
\text { Singh (2016) }\end{array}$ & 5.52 & 19.60 & 95 & 4.67 & 21.81 & 95 & 5.88 & 19.78 & 82 & 5.56 & 19.66 & 82 \\
\hline 9 & $\begin{array}{l}\text { Sadeghi dan Pow } \\
\text { (2015) }\end{array}$ & 5.78 & 11.22 & 35 & 5.78 & 17.05 & 35 & 6.85 & 11.17 & 35 & 6.73 & 11.37 & 35 \\
\hline 10 & $\begin{array}{l}\text { Otsuka, Hori, } \\
\text { dan Kawahito } \\
(2012)\end{array}$ & 5.00 & 19.16 & 19 & 5.95 & 19.11 & 19 & 19.32 & 19.32 & 19 & 4.64 & 20.74 & 19 \\
\hline 11 & $\begin{array}{l}\text { Soshani dan } \\
\text { Steinmetz (2013) }\end{array}$ & 5.78 & 22.51 & 537 & 5.62 & 23.85 & 537 & 5.79 & 23.06 & 501 & 6.09 & 23.58 & $\begin{array}{l}50 \\
1\end{array}$ \\
\hline 12 & $\begin{array}{l}\text { Wong, Owen, } \\
\text { Gabana, Brown, } \\
\text { Mcinnis, Toth, } \\
\text { dan Gilman } \\
(2016)\end{array}$ & 0.46 & 2.31 & 127 & 0.40 & 2.99 & 127 & 0.35 & 2.24 & 91 & 0.38 & 2.84 & 91 \\
\hline
\end{tabular}


Hasil pengolahan data pada 12 literatur yang digunakan dapat dilihat pada tabel 3. Berdasarkan tabel 3, dapat dilihat bahwa terdapat 7 literatur yang menyatakan efektivitas gratitude intervention pada well-being termasuk dalam kategori sedang hingga besar $(\mathrm{d}=$ 0,89 - -0,29). Sedangkan terdapat 5 literatur yang menyatakan efektivitas gratitude intervention pada well-being tergolong kategori kecil $(\mathrm{d}<0,2)$.

Tabel 3. Hasil Pengolahan Data (Cohen's d)

\begin{tabular}{|c|c|c|c|c|c|c|}
\hline Stratum & $\mathrm{N}(\operatorname{exptl.})$ & $\mathrm{N}(\mathrm{ctrl})$. & d & \multicolumn{2}{|c|}{ Approximate 95\% CI } & \\
\hline 1 & 30 & 25 & 0.793651 & 0.242557 & 1.344744 & $\begin{array}{l}\text { Duthley, Nunn, dan Avella } \\
\text { (2017) }\end{array}$ \\
\hline 2 & 47 & 40 & 0.276454 & -0.14717 & 0.700077 & $\begin{array}{l}\text { Watkins, Uhder, dan } \\
\text { Pichinevskiy(2014) }\end{array}$ \\
\hline 3 & 105 & 78 & 0.261724 & -0.032476 & 0.555925 & $\begin{array}{l}\text { Toepfer, Cichy, dan Peters } \\
\text { (2011) }\end{array}$ \\
\hline 4 & 28 & 28 & 0.074494 & -0.44951 & 0.598498 & $\begin{array}{l}\text { Rash, Matsuba, dan } \\
\text { Prkachin (2011) }\end{array}$ \\
\hline 5 & 40 & 48 & -0.068112 & -0.487836 & 0.351612 & Killen dan Macaskill (2014) \\
\hline 6 & 54 & 43 & 0.168877 & -0.23242 & 0.570174 & $\begin{array}{l}\text { Tyler, Renshaw, dan Rock } \\
\text { (2018) }\end{array}$ \\
\hline 7 & 24 & 21 & -0.187505 & -0.774436 & 0.399426 & Timmons dan Ekas (2018) \\
\hline 8 & 95 & 82 & 0.419653 & 0.120999 & 0.718308 & Khanna dan Singh (2016) \\
\hline 9 & 35 & 35 & 0.895437 & 0.403997 & 1.386876 & Sadeghi dan Pow (2015) \\
\hline 10 & 19 & 19 & -0.299092 & -0.938534 & 0.34035 & $\begin{array}{l}\text { Otsuka, Hori, dan Kawahito } \\
\text { (2012) }\end{array}$ \\
\hline 11 & 537 & 501 & 0.046108 & -0.07565 & 0.167866 & $\begin{array}{l}\text { Soshani dan Steinmetz } \\
\text { (2013) }\end{array}$ \\
\hline 12 & 127 & 91 & 0.381527 & 0.109968 & 0.653085 & $\begin{array}{l}\text { Wong, Owen, Gabana, } \\
\text { Brown, Mcinnis, Toth, dan } \\
\text { Gilman(2016) }\end{array}$ \\
\hline
\end{tabular}

\section{Effect size dan Confidence Interval (CI)}

Berdasarkan hasil pengolahan data untuk menguji effect size didapatkan nilai pooled $\mathrm{d}+$ sebesar $0.238184(\mathrm{~d}>0.2)$ dengan tingkat kepercayaan sebesar $95 \%$. Efektivitas gratitude intervention pada well-being berada pada kisaran 0.073476 to 0.402892. Hal ini menunjukkan efektivitas gratitude intervention pada well-being termasuk dalam kategori sedang. Kategori effect size gratitude intervention pada well-being dapat dilihat pada tabel 4 .

Tabel 4. Hasil Pengolahan Data (Cohen's $d$ )

\begin{tabular}{lllllll}
\hline Stratum & $\mathrm{N}$ (exptl.) & $\mathrm{N}($ ctrl. $)$ & $\mathrm{D}$ & \multicolumn{2}{l}{ Approximate 5 5\% CI } & Kategori \\
\hline 1 & 30 & 25 & 0.793651 & 0.242557 & 1.344744 & Sedang \\
2 & 47 & 40 & 0.276454 & -0.14717 & 0.700077 & Sedang \\
3 & 105 & 78 & 0.261724 & -0.032476 & 0.555925 & Sedang \\
4 & 28 & 28 & 0.074494 & -0.44951 & 0.598498 & Kecil \\
5 & 40 & 48 & -0.068112 & -0.487836 & 0.351612 & Kecil \\
6 & 54 & 43 & 0.168877 & -0.23242 & 0.570174 & Kecil \\
7 & 24 & 21 & -0.187505 & -0.774436 & 0.399426 & Kecil \\
8 & 95 & 82 & 0.419653 & 0.120999 & 0.718308 & Sedang \\
9 & 35 & 35 & 0.895437 & 0.4039997 & 1.386876 & Besar \\
10 & 19 & 19 & -0.299092 & -0.938534 & 0.34035 & Sedang \\
11 & 537 & 501 & 0.046108 & -0.07565 & 0.167866 & Kecil \\
12 & 127 & 91 & 0.381527 & 0.109968 & 0.653085 & Sedang
\end{tabular}

\section{Konsistensi Data dan Heterogenitas}

Hasil pengolahan data uji konsistensi menunjukkan nilai $I 2$ sebesar $60.4 \%$ dengan nilai keakuratan antara $8.7 \%$ hingga $77.4 \%$ dan nilai Cochran $Q$ sebesar 27.754555( $\mathrm{p}=0.0035, \mathrm{p}<0.05)$. Hal ini berarti data penelitian merupakan data heterogen.

\section{Bias Publikasi}

Hasil uji bias publikasi mendapatkan nilai Egger bias sebesar $1.020537(\mathrm{p}=0.2738, \mathrm{p}>0.05)$ dengan tingkat keakuratan berada di antara 0.943299 hingga 2.984374. Hasil ini berarti tidak terdapat bias pada publikasi.

\section{Forest Plot}

Berdasarkan dari gambar 1, dapat disimpulkan bahwa gratitude intervention cukup efektif untuk meningkatkan well-being. 


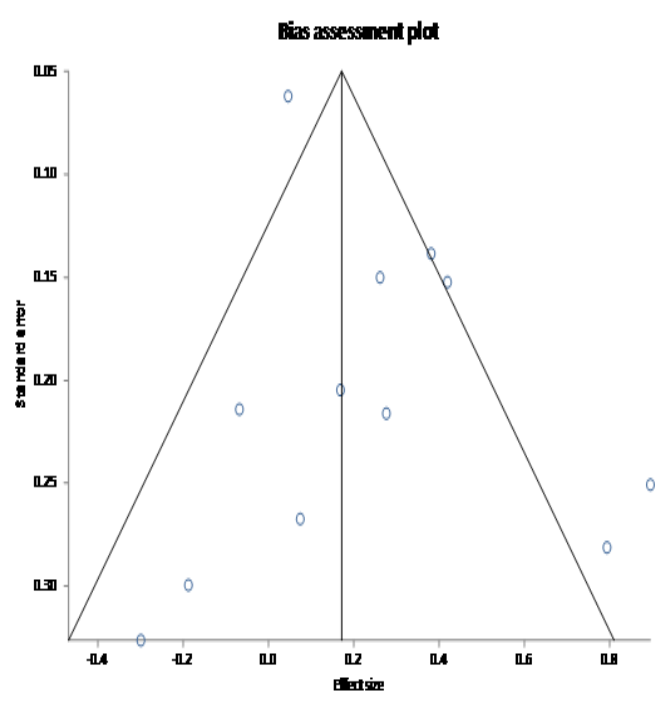

Gambar 1. Grafik Bias

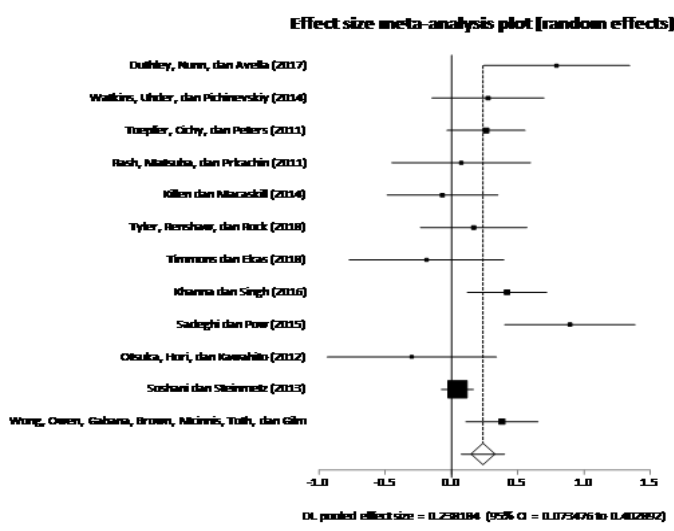

Gambar 2. Diagram Forest Plot

Meta analisis ini dilakukan dengan tujuan untuk mengetahui efektifitas gratitude intervention terhadap well-being individu. Berdasarkan meta analisis yang telah dilakukan kepada 12 literatur, didapatkan effect size gratitude intervention pada well-being termasuk dalam kategori sedang yang. dapat disimpulkan gratitude intervention cenderung dapat memberikan cukup pengaruh kepada tingkat wellbeing.individu.
Pemberian gratitude intervention cukup dapat meningkatkan tingkat wellbeing individu. Hal ini sejalan dengan hasil dari penelitian-penelitian terdahulu (Toepfer dan Walker, 2009; Sadeghi dan Pow, 2015, Duthely, Nun, dan Avella, 2017) yang menyatakan gratitude intervention berpengaruh secara signifikan terhadap well-being partisipan studi di penelitian mereka. Seperti dalam penelitian oleh Nelson (2009, disitat dalam Killen dan Macaskill, 2014) makin bertambahnya rasa bersyukur seorang individu, ketika individu mengalami pengalaman negatif, rasa bersyukur tersebut dapat menjadi peredam emosiemosi negatif yang muncul dalam diri individu.

Hal yang perlu diperhatikan dalam penelitian ini adalah heterogenitas data yang dimiliki oleh studi meta analisis. Heterogenitas data dalam studi ini adalah heterogen. Hal ini dapat disebabkan karena adanya perbedaan alat ukur yang digunakan dalam keduabelas literatur yang dianalisa.

\section{PENUTUP}

Hasil penelitian menemukan pemberian gratitude intervention memiliki pengaruh pada tingkat wellbeing individu. Hasil penelitian ini konsisten dengan penelitian-penelitian 
terdahulu mengenai efektivitas gratitude intervention pada well-being individu.

Kelebihan dari penelitian ini adalah tidak adanya bias dalam literatur yang digunakan di penelitian. Sedangkan kelemahan dari penelitian ini adalah data yang heterogen dalam penelitian. Selain itu, dalam penelitian ini analisis data yang dilakukan tidak membedakan alat ukur yang dipakai di literatur. Penelitian selanjutnya diharapkan untuk memperhatikan heterogenitas data dan lebih menspesifikkan jenis well-being dan gratitude intervention yang diteliti.

\section{DAFTAR PUSTAKA}

Diener, E., \& Chan, M.Y. 2011. Happy People Live Longer: Subjective WellBeing Contributes to Health and Longevity. Applied Psychology: Health and Well-Being, 3(1). 1-43

Duthely, L. M., Nunn, S. G., \& Avella, J. T. 2017. A Novel Heart-Centered, Gratitude-Meditation Intervention to Increase Well-Being among Adolescents. Education Research International, 1-12.

Emmons, R. A., \& Mccullough, M. E. 2003. Counting blessings versus burdens: An experimental investigation of gratitude and subjective well-being in daily life. Journal of Personality \& Social Psychology,84(2), 377-389.

Khanna, P., \& Singh, K. 2016. Effect of Gratitude Educational Intervention on Well-Being Indicators Among North Indian Adolescents. Contemporary
School Psychology,20(4), 305-314.

Killen, A., \& Macaskill, A. 2014. Using a Gratitude Intervention to Enhance Well-Being in Older Adults. Journal of Happiness Studies, 16(4), 947-964.

Otsuka, Y., Hori, M., \& Kawahito, J. 2012. Improving well-being with a gratitude exercise in Japanese workers: A randomized controlled trial. International Journal of Psychology and Counselling,4(7).

Rash, J. A., Matsuba, M. K., \& Prkachin, K. M. 2011. Gratitude and WellBeing: Who Benefits the Most from a Gratitude Intervention? Applied Psychology: Health and WellBeing,3(3), 350-369.

Renshaw, T. L., \& Rock, D. K. 2018. Effects of a brief grateful thinking intervention on college students' mental health. Mental Health \& Prevention,9, 19-24.

Sadeghi, A., \& Pow, S. B. 2015. The Effect of Gratitude on Psychological and Subjective Wellbeing among Hospital Staff. Health Education and Health Promotion (HEHP),3.

Shoshani, A., \& Steinmetz, S. 2013. Positive Psychology at School: A School- Based Intervention to Promote Adolescents' Mental Health and Well- Being. Journal of Happiness Studies, 15(6), 1289-1311.

Timmons, L., \& Ekas, N. V. 2018. Giving thanks: Findings from a gratitude intervention with mothers of children with autism spectrum disorder. Research in Autism Spectrum Disorders, 49, 13-24.

Toepfer, S., \& Walker, K. 2009. Letters of Gratitude: Improving Well-Being through Expressive Writing. Journal 
of Writing Research, 1(3), 181-198.

Toepfer, S. M., Cichy, K., \& Peters, P. 2011. Letters of Gratitude: Further Evidence for Author Benefits. Journal of Happiness Studies, 13(1), 187-201.

Watkins, P. C., Uhder, J., \& Pichinevskiy, S. 2014. Grateful recounting enhances subjective well-being: The importance of grateful processing. The Journal of Positive Psychology, 10(2), 91-98.

Wong, Y. J., Owen, J., Gabana, N. T., Brown, J. W., Mcinnis, S., Toth, P., \& Gilman, L. 2016. Does gratitude writing improve the mental health of psychotherapy clients? Evidence from a randomized controlled trial. Psychotherapy Research,28(2), 192202. 